Article

\title{
Improving the Solubility of Aripiprazole by Multicomponent Crystallization
}

\author{
Qi Zhou ${ }^{1,2}$, Zhongchuan Tan ${ }^{1,2}$, Desen Yang ${ }^{1,2}$, Jiyuan Tu ${ }^{1,2}$, Yezi Wang ${ }^{1,2}$, Ying Zhang ${ }^{1,2}$, Yanju Liu ${ }^{1,2, *}$ \\ and Guoping Gan 1,2,* \\ 1 Pharmacy Faculty, Hubei University of Chinese Medicine, Wuhan 430070, China; zhouqi0908@126.com (Q.Z.); \\ tanzhongchuan2021@163.com (Z.T.); yds22@126.com (D.Y.); 3070@hbtcm.edu.cn (J.T.); \\ WYZworkmail@163.com (Y.W.); zy09242021@163.com (Y.Z.) \\ 2 Technical Engineering Research Center of Traditional Chinese Medicine Processing in Hubei Province, \\ Wuhan 430070, China \\ * Correspondence: lyj1965954@hbtcm.edu.cn (Y.L.); ganguop@sina.com (G.G.)
}

check for updates

Citation: Zhou, Q.; Tan, Z.; Yang, D.; Tu, J.; Wang, Y.; Zhang, Y.; Liu, Y.; Gan, G. Improving the Solubility of Aripiprazole by Multicomponent Crystallization. Crystals 2021, 11, 343. https://doi.org/10.3390/ cryst11040343

Academic Editor: Emilio Parisini

Received: 27 February 2021

Accepted: 25 March 2021

Published: 28 March 2021

Publisher's Note: MDPI stays neutral with regard to jurisdictional claims in published maps and institutional affiliations.

Copyright: (C) 2021 by the authors. Licensee MDPI, Basel, Switzerland. This article is an open access article distributed under the terms and conditions of the Creative Commons Attribution (CC BY) license (https:/ / creativecommons.org/licenses/by/ $4.0 /)$.

\begin{abstract}
Aripiprazole (ARI) is a third-generation antipsychotic with few side effects but a poor solubility. Salt formation, as one common form of multicomponent crystals, is an effective strategy to improve pharmacokinetic profiles. In this work, a new ARI salt with adipic acid (ADI) and its acetone hemisolvate were obtained successfully, along with a known ARI salt with salicylic acid (SAL). Their comprehensive characterizations were conducted using X-ray diffraction and differential scanning calorimetry. The crystal structures of the ARI-ADI salt acetone hemisolvate and ARISAL salt were elucidated by single-crystal X-ray diffraction for the first time, demonstrating the proton transfer from a carboxyl group of acid to ARI piperazine. Theoretical calculations were also performed on weak interactions. Moreover, comparative studies on pharmaceutical properties, including powder hygroscopicity, stability, solubility, and the intrinsic dissolution rate, were carried out. The results indicated that the solubility and intrinsic dissolution rate of the ARI-ADI salt and its acetone hemisolvate significantly improved, clearly outperforming that of the ARI-SAL salt and the untreated ARI. The study presented one potential alternative salt of aripiprazole and provided a potential strategy to increase the solubility of poorly water-soluble drugs.
\end{abstract}

Keywords: aripiprazole; multicomponent crystal; crystal structure; solubility

\section{Introduction}

In the past few decades, a number of drugs have shown poor physicochemical properties, especially aqueous solubility and stability, often affecting their absorption in the gastrointestinal tract [1]. Multicomponent crystal formation is an effective strategy to improve pharmacokinetic profiles without altering the main chemical structures and inherent biological activity $[2,3]$. Co-crystals and salts are two common forms of multicomponent crystals which might have higher solubility and faster dissolution behavior compared to untreated drugs [4,5]. Compared to cocrystals, salt formation is the simplest and most cost-effective strategy and has significant advantages in addressing poor aqueous solubility because of ionizable drugs [6].

Aripiprazole (ARI), a third-generation antipsychotic, is a dopamine D2 receptor partial agonist and D1 receptor agonist which can ameliorate hyperprolactinemia induced by other antipsychotic drugs and cause fewer side effects, such as weight gain, diabetes, and dyslipidemia [7,8]. However, ARI belongs to the Biopharmaceutics Classification System (BCS) class II and its clinical use is limited by its poor aqueous solubility [9,10]. As a weakly basic drug, salt formation is one of the most popular and effective approaches to improve physicochemical properties, especially solubility $[6,11,12]$. Many salts of ARI have been reported. Freire et al. reported successively eight crystal structures of ARI salts with nitrate, perchlorate, oxalate, phthalate, homophthalate, thiosalicilate, and two 
different dihidrogenphosphates [13-16]. Nanubolu et al. reported five ARI salts with benzoic acid, 2,4-dihydroxy benzoic acid, 2,5-dihydroxy benzoic acid, salicylic acid, and hydrochloric acid [17]. However, these studies mainly focus on the structure illustration, and key pharmaceutical properties were not given. While Zhao et al. synthesized six ARI salts with gallic acid, 4-aminosalicylic acid, acetylsalicylic acid, maleic acid, fumaric acid, and malic acid and evaluated their solubility and dissolution profile [18], new ARI salts with ideal pharmaceutical properties are still in demand.

Continuing to explore the excellent salts of ARI, we successfully obtained a new ARI salt with adipic acid (ADI) and its acetone hemisolvate, along with a known ARI salt with salicylic acid (SAL). The molecular structures of the ARI and cocrystal formers (CCF) are displayed in Scheme 1. Their comprehensive characterizations were conducted using powder X-ray diffraction (PXRD) and differential scanning calorimetry (DSC). The crystal structures of the ARI-ADI salt acetone hemisolvate and ARI-SAL salt were elucidated by single-crystal X-ray diffraction (SXRD) for the first time. Furthermore, computational studies, including molecular electrostatic potential surface (MEPS) and Hirshfeld surface analysis (HSA), were applied to explore molecular interactions between the active pharmaceutical ingredient (API) and CCF. Above all, their pharmaceutical properties, such as powder hygroscopicity, stability, solubility, and the intrinsic dissolution rate (IDR), were evaluated. The results showed that the solubility and IDR of the ARI-ADI salt and its acetone hemisolvate significantly improved. This study provides a potential strategy to increase the solubility of poorly water-soluble drugs and gain a comprehensive understanding of the structure-property relationship.<smiles>O=C1CCc2ccc(OCCCCN3CCN(c4cccc(Cl)c4Cl)CC3)cc2N1</smiles>

Aripiprazole (ARI)<smiles>O=C(O)c1ccccc1O</smiles>

Salicylic acid (SAL)<smiles>O=C(O)CCCCC(=O)O</smiles>

Adipic acid (ADI)

Scheme 1. Molecular structures of aripiprazole and cocrystal formers.

\section{Materials and Methods}

\subsection{Materials}

The aripiprazole was purchased from Sun Chemical \& Technology (Shanghai, China) Co., Ltd., and the CCF were purchased from J\&K Scientific Ltd. (Beijing, China). All chemicals were used without further purification. All reagents used for this study were of analytical grade and purchased from Sinopharm Chemical Reagent Co., Ltd. (Shanghai, China). Purified water was prepared by Millipore UP Water Purification System (Merck, Kenilworth, NJ, USA). 


\subsection{Preparation of Multicomponent Crystals}

ARI-SAL salt. The equimolar amounts of ARI $(224.2 \mathrm{mg}, 0.5 \mathrm{mmol})$ and SAL $(69.1 \mathrm{mg}$, $0.5 \mathrm{mmol})$ were dissolved in $30 \mathrm{~mL}$ of acetonitrile-water mixed solvent $(v / v, 1: 1)$ at $60^{\circ} \mathrm{C}$. The resulting solution was filtered and then kept for eight days at $35^{\circ} \mathrm{C}$. White block crystals were obtained. The bulk samples were prepared by slurry method. A mixture of ARI ( $448 \mathrm{mg}, 1 \mathrm{mmol})$ and SAL (138 mg, $1 \mathrm{mmol})$ was added to $6 \mathrm{~mL}$ of acetonitrile-water mixed solvent $(v / v, 1: 1)$ and stirred for $12 \mathrm{~h}$ at a speed of $350 \mathrm{rpm}$. The solid obtained by filtering the solution was dried to a constant weight in a vacuum oven at $30^{\circ} \mathrm{C}$.

ARI-ADI salt acetone hemisolvate. The mixture of ARI $(224.2 \mathrm{mg}, 0.5 \mathrm{mmol})$ and ADI ( $36.5 \mathrm{mg}, 0.25 \mathrm{mmol})$ was dissolved in $20 \mathrm{~mL}$ of acetone at $60^{\circ} \mathrm{C}$. The resulting solution was filtered and then kept for four days at $35^{\circ} \mathrm{C}$. White block crystals were obtained. The bulk samples were prepared by slurry method. A mixture of ARI ( $448 \mathrm{mg}, 1 \mathrm{mmol})$ and ADI $(73 \mathrm{mg}, 0.5 \mathrm{mmol})$ was added into $6 \mathrm{~mL}$ of acetone solution and stirred for $12 \mathrm{~h}$ at a speed of $350 \mathrm{rpm}$. The solid obtained by filtering the solution was dried to a constant weight in a vacuum oven at $30^{\circ} \mathrm{C}$.

Additionally, ARI-ADI salt was obtained by drying ARI-ADI salt acetone hemisolvate in a vacuum oven at $70{ }^{\circ} \mathrm{C}$ for $2 \mathrm{~h}$.

\subsection{Characterization}

\subsubsection{Single Crystal X-ray Diffraction (SXRD)}

The crystal structures were determined with a Bruker APEX-II CCD diffractometer using graphite monochromatic Mo-K $\alpha$ radiation $(\lambda=0.71073 \AA)$ at $296 \mathrm{~K}$. Frame integration was performed using SAINT (version 7.68A) [19]. The resulting raw data were scaled and the absorption was corrected using a multi-scan averaging of symmetry-equivalent data by SADABS [20]. The structure was solved by the direct method with the olex2 software and then refined via full-matrix least-squares procedures using SHELXL-2014 on F2 with anisotropic displacement parameters (ADPs) for non-hydrogen atoms [21,22]. The $\mathrm{H}$ atoms were located in idealized difference Fourier maps and refined as riding models with isotropic thermal parameters $(\operatorname{Uiso}(\mathrm{H})=1.2 \mathrm{Ueq}(\mathrm{C})$, Uiso $(\mathrm{H})=1.2 \mathrm{Ueq}(\mathrm{N})$, and $\operatorname{Uiso}(\mathrm{H})=1.5 \mathrm{Ueq}(\mathrm{O}))$.

Diamond [23] (version 4.6.3, Crystal Impact GbR, Bonn, Germany) was used for preparing crystal packing diagrams.

\subsubsection{Powder X-ray Diffraction (PXRD)}

Powder X-ray diffraction (PXRD) patterns were recorded on a Bruker D8 ADVANCE $\mathrm{X}$-ray powder diffractometer (Bruker, Germany) with $\mathrm{Cu}-\mathrm{K} \alpha$ radiation at $40 \mathrm{KV}$ and $40 \mathrm{~mA}$. After sieving through $100 \mathrm{mesh}$, about $50 \mathrm{mg}$ samples were measured in the 2-theta range of $5-50^{\circ}$ at a scan rate of $8^{\circ} / \mathrm{min}$.

\subsubsection{Differential Scanning Calorimetry (DSC)}

DSC analyses were taken on a Mettler Toledo DSC1 instrument (Mettler, Zurich, Switzerland). An amount of 3 5 mg samples were put into aluminum pans with pinhole lids and heated in the $30 \sim 300^{\circ} \mathrm{C}$ temperature range at a constant heating rate of $10^{\circ} \mathrm{C} / \mathrm{min}$ under a nitrogen flux of $50 \mathrm{~cm}^{3} / \mathrm{min}$.

\subsection{Computational Studies}

\subsubsection{Acid Dissociation Constant (pKa)}

The formation of the resultant supramolecules can be predicted according to the $\mathrm{pKa}$ difference $(\Delta \mathrm{pKa}=\mathrm{pKa}[$ base $]-\mathrm{pKa}[$ acid] $)$ of corresponding acid/base pairs [24,25]. It is generally accepted that a salt will be formed if the $\Delta \mathrm{pKa}$ value is greater than 3 , and a $\Delta \mathrm{pKa}$ value less than 0 will lead to the formation of cocrystals. However, if the $\Delta \mathrm{pKa}$ value is in the range of $0 \sim 3$, it will be not accurate to predict the resulting formation [25]. The pKa values of ARI and CCF were calculated by MarvinSketch 15.6.29 (ChemAxon, Budapest, Hungary) [26]. 


\subsubsection{Molecular Electrostatic Potential Surface (MEPS)}

The molecular structures of ARI and CCF were extracted from their crystal structures. Full geometry optimization and wave functions were performed by density function theory (DFT) using the B3LYP hybrid functional with 6-311G(d) basis set in the Gaussian 09 software. MEPS was mapped on the 0.001 a.u. electron density isosurface and analyzed by the Multiwfn program [27] and VWD program [28].

\subsubsection{Hirshfeld Surface Analysis (HSA)}

HSA and fingerprint plots were performed by CrystalExplorer 17.5 software [29], providing information about the nature of intermolecular interactions and their quantitative contribution to the Hirshfeld surface [30].

\subsection{Powder Hygroscopicity}

Dry glass weighing bottles (outside diameter $50 \mathrm{~mm}$, height $25 \mathrm{~mm}$ ) were placed in a dryer with ammonium chloride saturated solution at $25^{\circ} \mathrm{C} \pm 1{ }^{\circ} \mathrm{C}$ and weighed (m1) after $24 \mathrm{~h}$ of storage. Then, about $100 \mathrm{mg}$ samples were put into the bottles and weighed accurately (m2), respectively. After storage at the aforementioned conditions with the caps opened for $24 \mathrm{~h}$, each sample was weighed again (m3). The hygroscopicity could be calculated by the following equation.

$$
\text { Mass Change }(\%)=(\mathrm{m} 3-\mathrm{m} 1) /(\mathrm{m} 2-\mathrm{m} 1) \times 100 \% \text {. }
$$

\subsection{Stability Test}

The stabilities of ARI-SAL salt and ARI-ADI salt acetone hemisolvate were studied under high-temperature $\left(60 \pm 1{ }^{\circ} \mathrm{C}\right)$ and high-humidity $(95 \pm 5 \%)$ tests. Materials were randomly selected and exposed to high temperature and high humidity conditions. The storage times were 10 days and PXRD was applied to measure the final samples.

\subsection{Solubility Experiment}

\subsubsection{Solubility Test}

The solubility measurements were performed under water ( $\mathrm{pH} 7.0)$, hydrochloric acid buffer ( $\mathrm{pH} 1.2$ ), acetate acid-sodium acetate buffered solution ( $\mathrm{pH} 4.5)$, and phosphate buffer solution ( $\mathrm{pH} 6.8$ ), respectively. An excess number of samples were added to a test tube containing $10 \mathrm{~mL}$ of solvent and the tube was shaken in an orbital shaker $\left(37 \pm 0.5^{\circ} \mathrm{C}\right)$ until reaching the equilibrium condition $(48 \mathrm{~h})$. The solution was filtered through a $0.45 \mu \mathrm{m}$ mixed cellulose ester membrane and then analyzed by HPLC (LC-20, Shimadzu, Japan) equipped with a SP-20 ultraviolet detector at $254 \mathrm{~nm}$ wavelength. Quantitative tests were performed on a YMC C8 column $(250 \times 4.6 \mathrm{~mm}, 5 \mu \mathrm{m})$ with an external standard method. The mobile phase consisted of acetonitrile and water (containing $0.1 \%$ trimethylamine) $(65: 35, v / v)$, with a flow rate of $1.0 \mathrm{~mL} / \mathrm{min}$. Each test was performed in triplicate.

\subsubsection{Intrinsic Dissolution Rate (IDR) Test}

IDR is a key physicochemical parameter commonly used to assess in vivo dissolution and reflect bioavailability of drugs [31]. In this work, IDR was measured by the rotary basket method, which was applied to distinguish their dissolution properties. Prior to the IDR test, round discs of the samples should be compressed with a hydraulic press (Jintan Ruiding Machinery Co., Ltd. Changzhou, China). Specifically, $300 \mathrm{mg}$ samples were compressed at a pressure of $115.2 \mathrm{MPa}$ for $10 \mathrm{~s}$ to form smooth discs $8 \mathrm{~mm}$ in diameter. The acquired discs were coated with beeswax on three sides. The intrinsic dissolution study was performed at $100 \mathrm{rpm}$ in $500 \mathrm{~mL}$ of hydrochloric acid buffer $(\mathrm{pH} 1.2)$ as a dissolution medium at $37^{\circ} \mathrm{C}$. The ARI concentration in solution was measured at the predetermined time interval by the same analysis method as the solubility test. The sink conditions were maintained during the entire dissolution experiment, and each test was performed in triplicate. 


\section{Results and Discussion}

\subsection{Characterization}

\subsubsection{SXRD Analysis}

The crystal structures revealed that both ARI-SAL salt and ARI-ADI salt acetone hemisolvate were salts and the protonation occurred at the $\mathrm{N}_{2}$ atom, forming a strong charge assisted hydrogen bond formed by the strongest acceptor from the carboxylate anion interacting with strongest $\mathrm{N}^{+}-\mathrm{H}$ donor of piperazinium (see Appendix A). The crystallographic data are listed in Table 1 and the hydrogen bonding parameters are given in Table 2. The $\mathrm{C}_{16}-\mathrm{H}_{16 \mathrm{~A}} \cdots \mathrm{Cl}_{1}$ hydrogen bonds in Table 2 correspond to the typical intramolecular interaction characteristic of the dichlorophenyl-1-piperazinyl group in all reported ARI variants [16-18].

Table 1. Crystallographic data of two multicomponent crystals of aripiprazole.

\begin{tabular}{|c|c|c|}
\hline Compound Reference & ARI-SAL Salt & ARI-ADI Salts Acetone Hemisolvate \\
\hline Chemical formula & $\mathrm{C}_{23} \mathrm{H}_{28} \mathrm{Cl}_{2} \mathrm{~N}_{3} \mathrm{O}_{2} \cdot \mathrm{C}_{7} \mathrm{H}_{5} \mathrm{O}_{3}$ & $\mathrm{C}_{23} \mathrm{H}_{28} \mathrm{Cl}_{2} \mathrm{~N}_{3} \mathrm{O}_{2} \cdot 0.5\left(\mathrm{C}_{6} \mathrm{H}_{8} \mathrm{O}_{4}\right) \cdot 0.5\left(\mathrm{C}_{3} \mathrm{H}_{6} \mathrm{O}\right)$ \\
\hline Formula mass & 586.49 & 550.48 \\
\hline Crystal system & monoclinic & triclinic \\
\hline Space group & $\mathrm{P} 2{ }_{1} / \mathrm{c}$ & P-1 \\
\hline $\mathrm{a} / \AA$ & $15.082(2)$ & $7.6388(12)$ \\
\hline $\mathrm{b} / \AA$ & $9.6912(13)$ & $10.7268(17)$ \\
\hline $\mathrm{c} / \AA$ & $21.220(3)$ & $18.390(3)$ \\
\hline$\alpha /^{\circ}$ & 90 & $97.229(3)$ \\
\hline$\beta /^{\circ}$ & $106.743(2)$ & $93.641(3)$ \\
\hline$\gamma /{ }^{\circ}$ & 90 & $105.529(3)$ \\
\hline Unit cell volume $/ \AA^{3}$ & $2970.1(7)$ & $1432.9(4)$ \\
\hline Temperature/k & $296(2)$ & $296(2)$ \\
\hline No. of formula units per unit cell, $\mathrm{Z}$ & 4 & 2 \\
\hline Crystal density $\left(\mathrm{g} / \mathrm{cm}^{3}\right)$ & 1.312 & 1.276 \\
\hline No. of reflections measured & 9612 & 7725 \\
\hline No. of independent reflections & 6483 & 4047 \\
\hline $\mathrm{R}_{\text {int }}$ & 0.0289 & 0.0321 \\
\hline Final $R_{1}$ values $(\mathrm{I}>2 \sigma(\mathrm{I}))$ & 0.0806 & 0.0689 \\
\hline Final $w_{R}(F 2)$ values $(\mathrm{I}>2 \sigma(\mathrm{I}))$ & 0.2526 & 0.2135 \\
\hline Final $R_{1}$ values (all data) & 0.1127 & 0.1308 \\
\hline Final $w_{R}(F 2)$ values (all data) & 0.2848 & 0.2725 \\
\hline $\mathrm{F}(000)$ & 1232 & 582 \\
\hline Goodness of fit on F2 & 1.084 & 0.963 \\
\hline CCDC Number & 1991810 & 2023732 \\
\hline
\end{tabular}

ARI-SAL salt. The ARI-SAL salt crystallized in the monoclinic $\mathrm{P} 22_{1} / \mathrm{c}$ space group with an aripiprazole cation, balanced by a salicylic counter-ion, in the asymmetric unit (Figure 1a). The $\mathrm{O}_{5}$ atom of salicylic anion presented positional disorder over two sites with a 0.6: 0.4 site-occupancy. ARI-SAL salt, like other lactam compounds, formed a centrosymmetric $\mathrm{N}_{1}-\mathrm{H}_{1} \cdots \mathrm{O}_{1}$ dimer $R_{2}^{2}(8)$ motif with its inversion-related molecule [32]. Interestingly, the dimer formed a $1 \mathrm{D}$ ribbon through the short $\mathrm{Cl}_{1} \cdots \mathrm{O}_{1}$ interaction, which formed another new dimeric substructure (Figure 2a). Furthermore, the dimer units were arranged helically into the three-dimensional network (Figure 2b) by the bifurcated $\mathrm{N}-\mathrm{H} \cdots \mathrm{O}$ hydrogen bonds $\left(\mathrm{N}_{2}{ }^{+}-\mathrm{H}_{2} \cdots \mathrm{O}_{3}-\right.$ and $\mathrm{N}_{2}-\mathrm{H}_{2} \cdots \mathrm{O}_{4}$ hydrogen bond) and two weaker $\mathrm{C}-\mathrm{H} \cdots \mathrm{O}$ interactions $\left(\mathrm{C}_{27}-\mathrm{H}_{27} \cdots \mathrm{O}_{1}\right.$ and $\mathrm{C}_{17}-\mathrm{H}_{17 \mathrm{~A}} \cdots \mathrm{O}_{5}$ hydrogen bond), which generated two types of helices propagated along the b axis (Figure 2c,d). 
Table 2. Main hydrogen bonding parameters of two multicomponent crystals of ARI.

\begin{tabular}{|c|c|c|c|c|c|}
\hline & D-H $\cdots A$ & D-H/Å & $\mathbf{H} \cdots \mathbf{A} / \AA ̊$ & $\mathbf{D} \cdots \mathbf{A} / \AA ̊ \AA$ & $\mathrm{D}-\mathrm{H} \cdots \mathbf{A} /^{\circ}$ \\
\hline \multirow[t]{7}{*}{ ARI-SAL Salt } & $\mathrm{C}_{16}-\mathrm{H}_{16 \mathrm{~A}} \cdots \mathrm{Cl}_{1}$ & 0.97 & 2.675 & 3.248 & 118 \\
\hline & $\mathrm{O}_{5}-\mathrm{H}_{5} \cdots \mathrm{O}_{4}$ & 0.82 & 1.789 & 2.497 & 143 \\
\hline & $\mathrm{N}_{2}-\mathrm{H}_{2} \cdots \mathrm{O}_{3}$ & 0.98 & 1.691 & 2.670 & 177 \\
\hline & $\mathrm{N}_{2}-\mathrm{H}_{2} \cdots \mathrm{O}_{4}$ & 0.98 & 2.503 & 3.122 & 121 \\
\hline & $\mathrm{N}_{1}-\mathrm{H}_{1} \cdots \mathrm{O}_{1}^{\mathrm{i}}$ & 0.86 & 2.062 & 2.908 & 168 \\
\hline & $\mathrm{C}_{17}-\mathrm{H}_{17 \mathrm{~A}} \cdots \mathrm{O}_{5}{ }^{\mathrm{ii}}$ & 0.97 & 2.542 & 3.467 & 160 \\
\hline & $\mathrm{C}_{27}-\mathrm{H}_{27} \cdots \mathrm{O}_{1}{ }^{\mathrm{iii}}$ & 0.93 & 2.360 & 3.287 & 174 \\
\hline \multicolumn{6}{|c|}{ Symmetry transformation: ${ }^{\mathrm{i}}$ : $-\mathrm{x}+2,-\mathrm{y},-\mathrm{z}+1 ;{ }^{\mathrm{ii}}$ : $-\mathrm{x}+1, \mathrm{y}-1 / 2,-\mathrm{z}+3 / 2 ;{ }^{\mathrm{iii}}$ : $-\mathrm{x}+2, \mathrm{y}+1 / 2,-\mathrm{z}+3 / 2$. } \\
\hline \multirow{5}{*}{$\begin{array}{l}\text { ARI-ADI salt } \\
\text { acetone } \\
\text { hemisolvate }\end{array}$} & $\mathrm{C}_{16}-\mathrm{H}_{16 \mathrm{~A}} \cdots \mathrm{Cl}_{1}$ & 0.97 & 2.595 & 3.214 & 121 \\
\hline & $\mathrm{N}_{1}-\mathrm{H}_{1} \cdots \mathrm{O}_{1}{ }^{\mathrm{i}}$ & 0.86 & 2.023 & 2.869 & 167 \\
\hline & $\mathrm{N}_{2}-\mathrm{H}_{2} \cdots \mathrm{O}_{3}$ & 0.98 & 1.729 & 2.685 & 164 \\
\hline & $\mathrm{C}_{15}-\mathrm{H}_{15 \mathrm{~A}} \cdots \mathrm{Cl}_{1}^{\mathrm{ii}}$ & 0.97 & 2.957 & 3.448 & 112 \\
\hline & $\begin{array}{c}\mathrm{C}_{11^{-}} \\
\mathrm{H}_{11 \mathrm{~A}} \cdots \pi(\mathrm{Cg})^{\mathrm{iii}}\end{array}$ & 0.97 & 2.96 & 3.843 & 151 \\
\hline
\end{tabular}

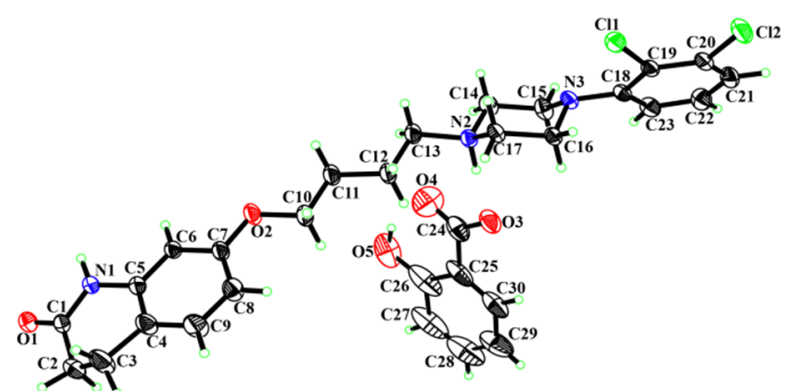

(a)

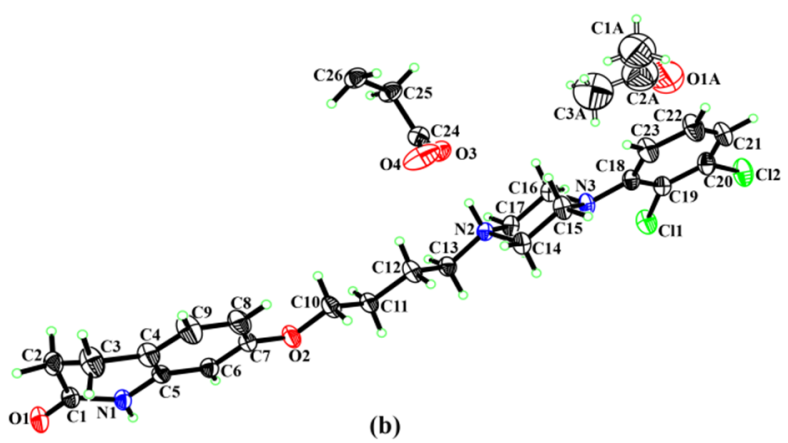

Figure 1. The molecular structures of two ARI multicomponent crystals with displacement ellipsoids drawn at the $30 \%$ probability level: (a) ARI-SAL salt; (b) ARI-ADI salt acetone hemisolvate.

ARI-ADI salt acetone hemisolvate. The ARI-ADI salt acetone hemisolvate crystallized in the triclinic P-1 space group. The ORTEP diagram contained an aripiprazole cation, half of an adipic acid counter-ion (bisected by an inversion center), and half of an acetone molecule (Figure $1 b$ ). The solvent acetone molecule was disordered with a position occupancy of 0.5 due to the location on the symmetric center, and acted as a filler in spatial network. The centrosymmetric $\mathrm{N}_{1}-\mathrm{H}_{1} \cdots \mathrm{O}_{1}$ dimer $R_{2}^{2}(8)$ motif with its inversion-related molecule also can be found and formed a 1D ribbon by the strongest charged $\mathrm{N}_{2}{ }^{+}-\mathrm{H}_{2} \cdots \mathrm{O}_{3}$ hydrogen bond (Figure $3 \mathrm{a}$ ). The $1 \mathrm{D}$ ribbon interacted with its adjacent ribbon and then formed a $2 \mathrm{D}$ sheet through a $\mathrm{C}_{15}-\mathrm{H}_{15 \mathrm{~A}} \cdots \mathrm{Cl}_{1}$ hydrogen bond (Figure $3 \mathrm{~b}$ ). Finally, the $2 \mathrm{D}$ sheets were arranged into the three-dimensional network by a weak $\mathrm{C}_{11}-\mathrm{H}_{11 \mathrm{~A}} \cdots \pi$ hydrogen bond (Figure 3c). 


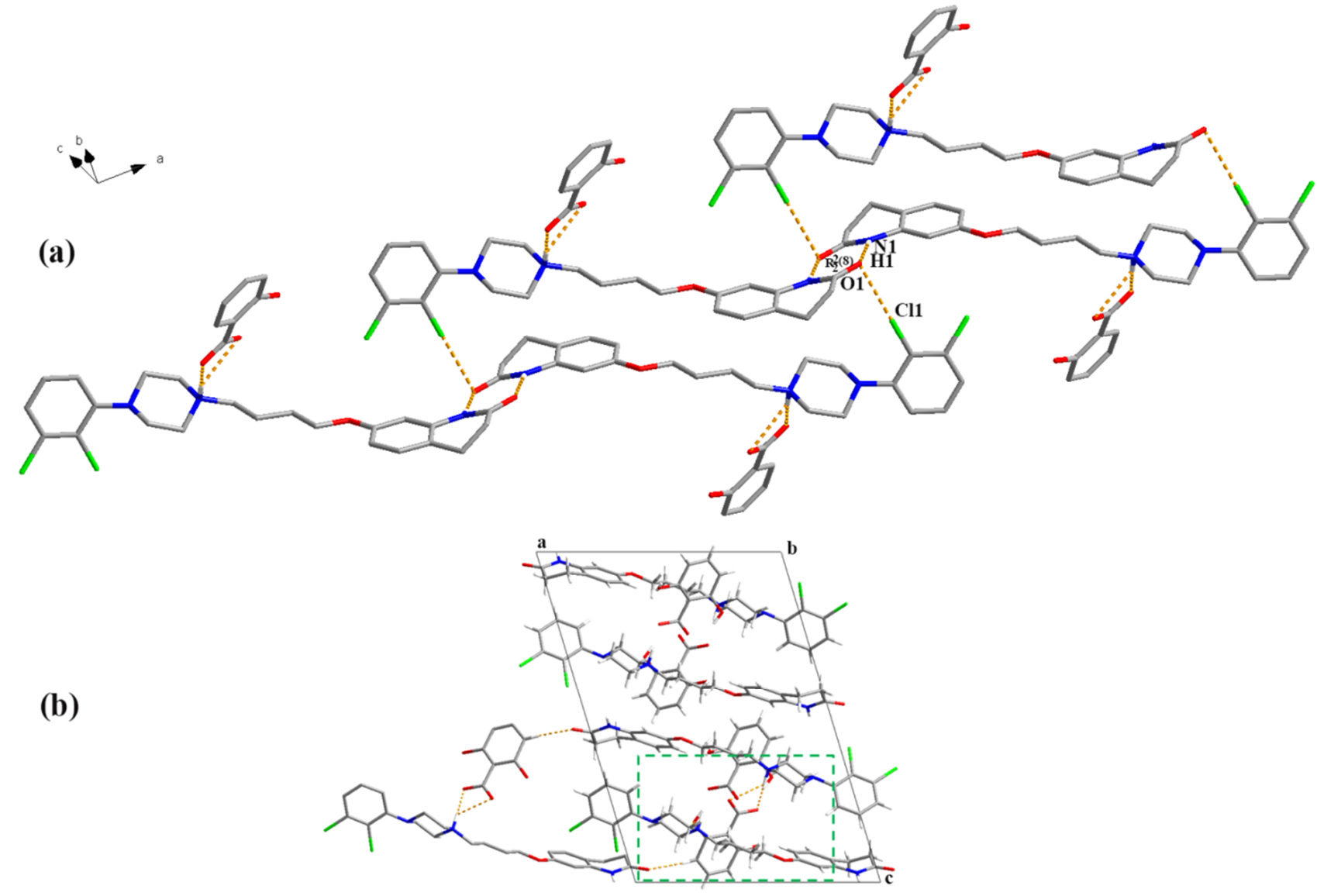

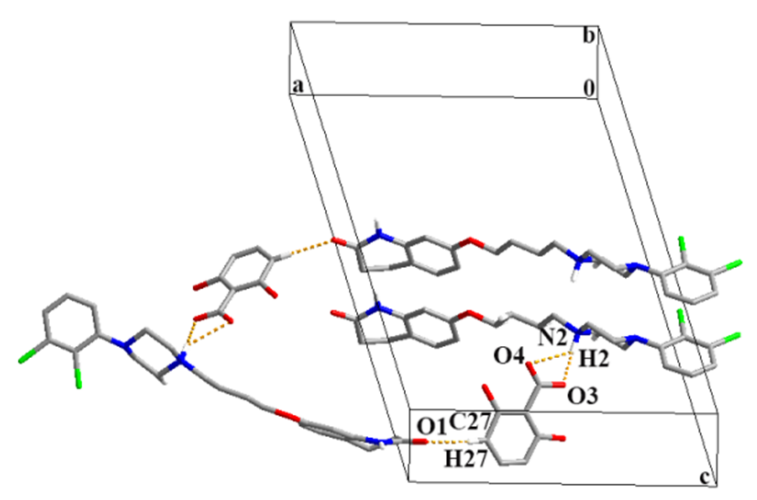

(c)

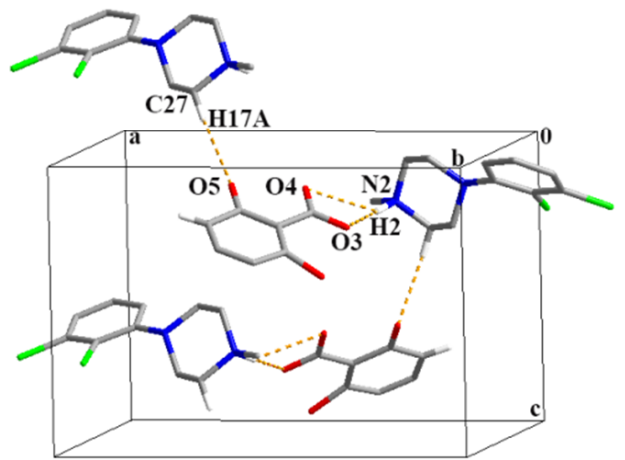

(d)

Figure 2. Packing diagrams of ARI-SAL salt: (a) the $1 \mathrm{D}$ ribbon was formed by $\mathrm{N}_{1}-\mathrm{H}_{1} \cdots \mathrm{O}_{1}$ hydrogen bond and short $\mathrm{Cl}_{1} \cdots \mathrm{O}_{1}$ interaction; (b) packing diagram for ARI-SAL salt viewed down the $\mathrm{b}$ axis and the green dashed wireframe indicates two different types of helices; (c) the type-1 helix was propagated by the bifurcated $\mathrm{N}-\mathrm{H} \cdots \mathrm{O}$ hydrogen bond and weaker $\mathrm{C}_{27}-\mathrm{H}_{27} \cdots \mathrm{O}_{1}$ interactions; (d) the type-2 helix was propagated by the bifurcated $\mathrm{N}-\mathrm{H} \cdots \mathrm{O}$ hydrogen bond and $\mathrm{C}_{17}-\mathrm{H}_{17 \mathrm{~A}} \cdots \mathrm{O}_{5}$ interactions (only a partial aripiprazole molecule was drawn for clarity). 


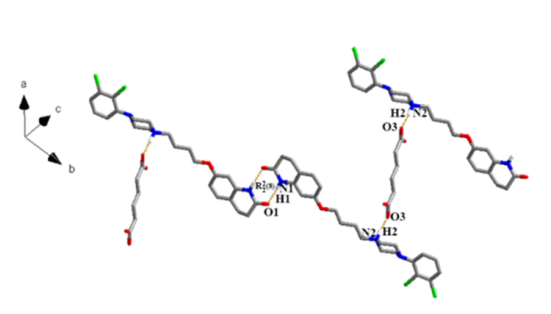

(a)

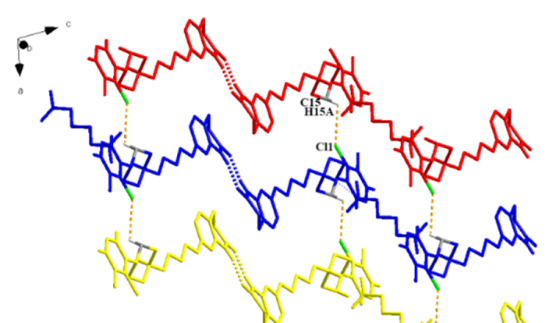

(b)

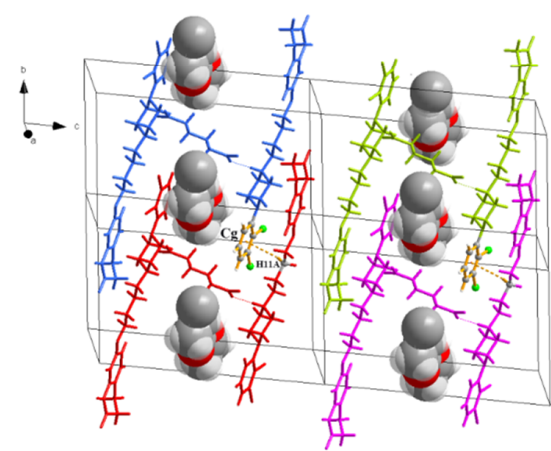

(c)

Figure 3. Packing diagrams of ARI-ADI salt acetone hemisolvate: (a) the $1 \mathrm{D}$ ribbon formed by $\mathrm{N}_{1}-\mathrm{H}_{1} \cdots \mathrm{O}_{1}$ and $\mathrm{N}_{2}-\mathrm{H}_{2} \cdots \mathrm{O}_{3}$ hydrogen bond; $(\mathbf{b})$ the $2 \mathrm{D}$ sheet formed by $\mathrm{C}_{15}-\mathrm{H}_{15 \mathrm{~A}} \cdots \mathrm{Cl}_{1}$ hydrogen bond; (c) packing diagram for ARI-ADI salt acetone hemisolvate formed by $\mathrm{C}_{11}-\mathrm{H}_{11 \mathrm{~A}} \cdots \mathrm{Cg}$ hydrogen bond.

\subsubsection{PXRD Analysis}

The ARI multicomponent crystals were synthesized and characterized by PXRD. As seen in Figure 4, their experimental patterns show significant differences compared with those of ARI, which are confirmed as new crystalline forms due to the absence of the characteristic peak of ARI at $20.483^{\circ}$ and $22.199^{\circ}$. The characteristic PXRD peaks of the ARI-SAL salt were $12.948^{\circ}, 18.401^{\circ}$, and $19.849^{\circ}$, while those of the ARI-ADI salt were $25.079^{\circ}, 14.976^{\circ}$, and $18.256^{\circ}$, which were different from those of its acetone hemisolvte with characteristic PXRD peaks at $18.197^{\circ}$ and $24.897^{\circ}$. Importantly, the experimental patterns of ARI-ADI salt acetone hemisolvate and ARI-SAL salt coincided well with their own calculated PXRD patterns from single crystal structures, indicating that the bulk pure samples were prepared successfully.

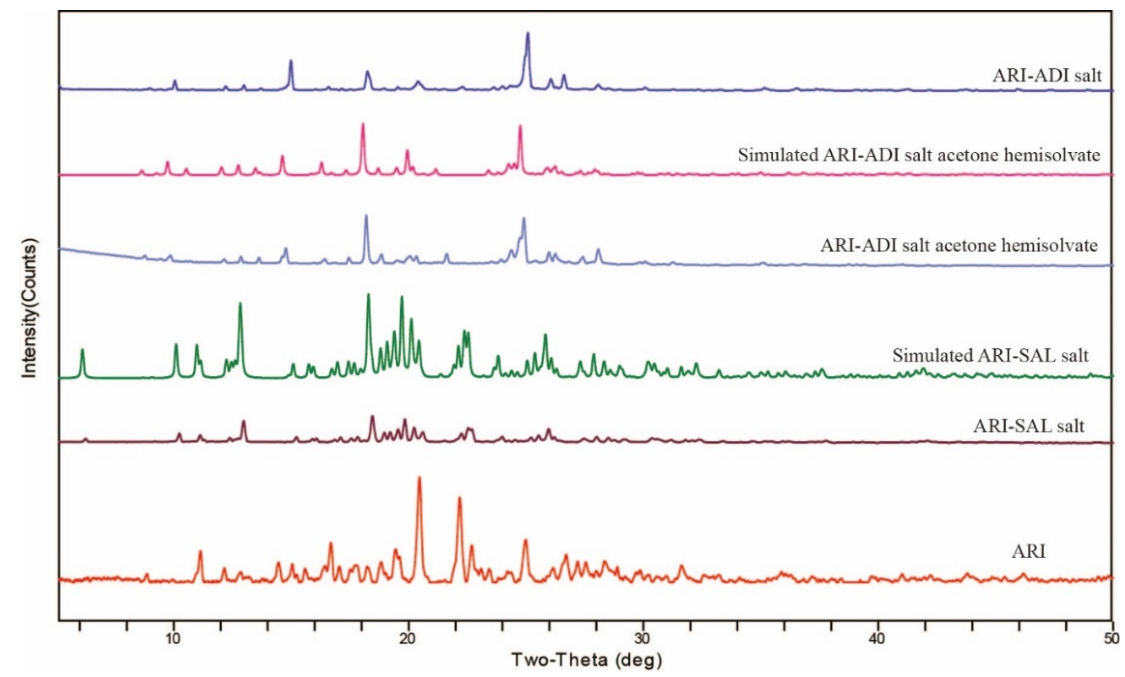

Figure 4. PXRD patterns of ARI and its crystal salts. 


\subsubsection{DSC Analysis}

As reported by Zhao Yanxiao [18], the DSC thermogram (Figure 5) of ARI exhibited two endothermic peaks and a small exothermic peak. The endothermic peak at $138.94{ }^{\circ} \mathrm{C}$ corresponded to the melting point of form III, while the second endothermic peak at $147.79^{\circ} \mathrm{C}$ represented the melting point of form I, demonstrating that form III might be transformed to form I during the heating process. As expected, the DSC thermograms of ARI multicomponent crystals were distinct from those of ARI and CCF. A single melting endothermic peak was observed at $182.38^{\circ} \mathrm{C}$ for the ARI-SAL salt, indicating the formation of pure solid phase. For the ARI-ADI salt acetone hemisolvate, a weak endothermic event of desolvation and a sharp melting endothermic peak were observed at $57.43{ }^{\circ} \mathrm{C}$ and $121.18^{\circ} \mathrm{C}$, respectively, which implied that it had a poor thermodynamic stability and may transform into a desolvated salt. As we intended, the ARI-ADI salt showed a single melting endothermic peak at $120.36^{\circ} \mathrm{C}$.

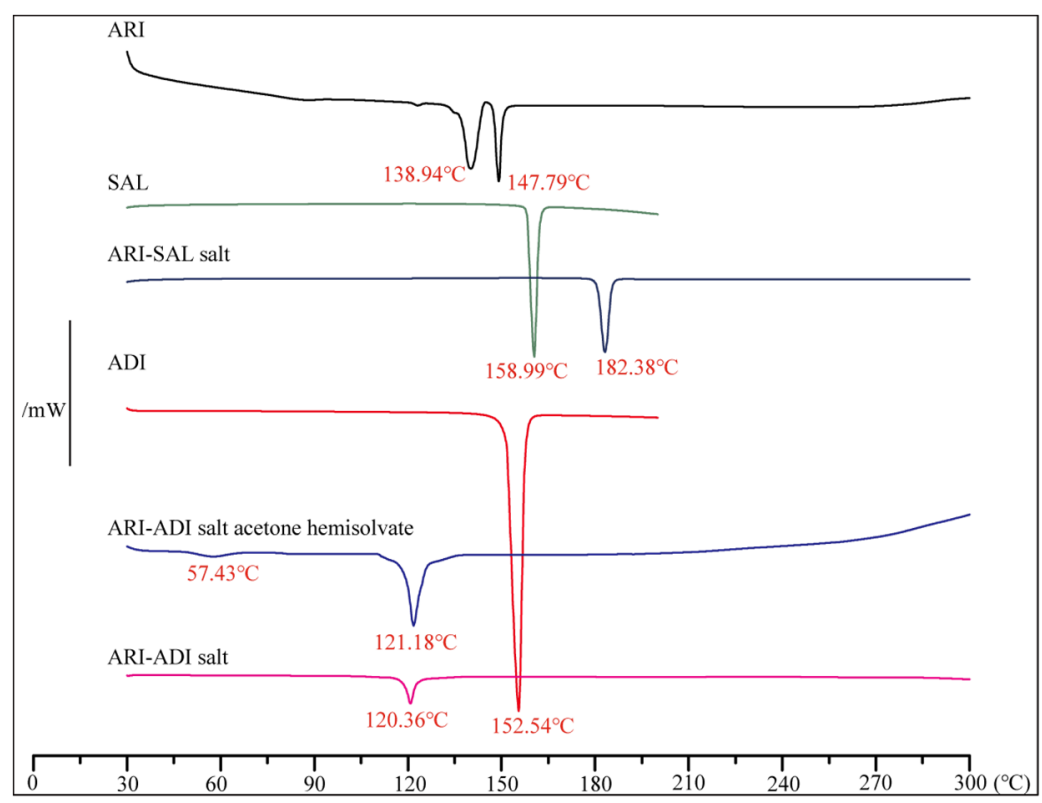

Figure 5. DSC thermograms of ARI, CCF, and its crystal salts.

\subsection{Theoretical Calculation}

\subsubsection{Acid Dissociation Constant (pKa)}

ARI is a weak base with a pKa of 7.46, and both salicylic acid and adipic acid are weak acid excipients with $\mathrm{pKa}$ values of 2.79 and 3.92 , respectively. According to the $\Delta \mathrm{pKa}$ rule, if the difference of $\mathrm{pKa}$ between active pharmaceutical ingredients and CCF was greater than 3, the binary mixture tended to form a salt type [25]. Therefore, we predicted that both of the synthesized multicomponent crystals of ARI were salts, which could be confirmed by especially single-crystal X-ray diffraction.

\subsubsection{Molecular Electrostatic Potential Surface}

MEPs can provide some clear information in terms of the electrophilic and nucleophilic attack region of the molecule. The values of MEP, related to the strength of intermolecular interactions, can predict the formation possibility of multicomponent crystals. The MEPs mapped on van der waals (VDW) surface of ARI, SAL, and ADI are given in Figure 6, where the red color represents a positive electrical potential and the blue color represents a negative electrical potential. The pKa values were calculated by MarvinSketch and are presented in the black color. 


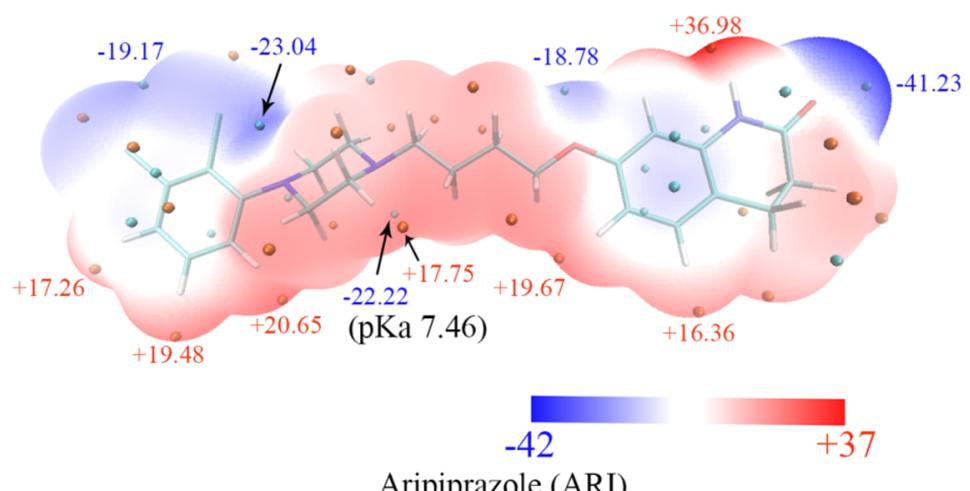

Aripiprazole (ARI)

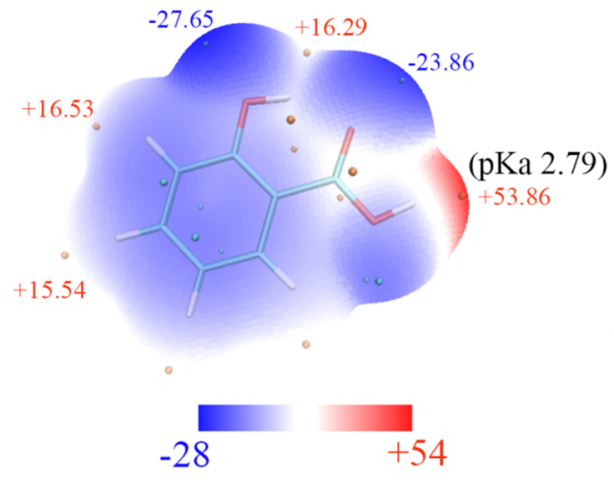

Salicylic acid (SAL)

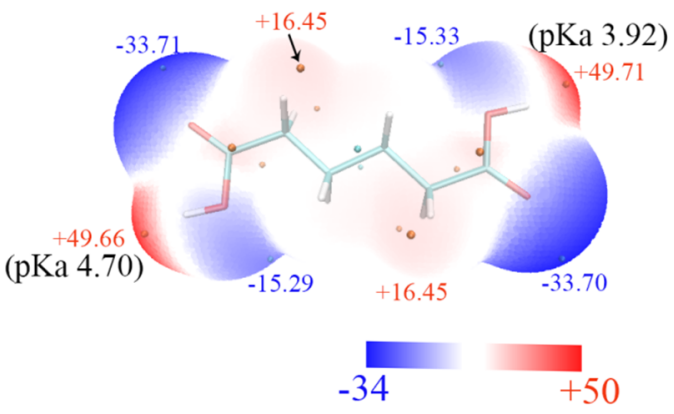

Adipic acid (ADI)

Figure 6. Electrostatic potential mapped onto the 0.001 a.u. electron density isosurface of ARI, SAL, and ADI. The maximal and minimal extreme points of electrical potential are marked with red and blue, repectively. The pKa values are presented in black.

As reported by Zhao Yanxiao [18], the global maxima and minima values of the electrostatic potential on the surface in ARI were +36.98 and $-41.23 \mathrm{kcal} / \mathrm{mol}$, which corresponded to carbonyl and amino group of the lactam ring, respectively, and formed the $\mathrm{N}-\mathrm{H} \cdots \mathrm{O}$ homodimers as evidenced in this study. The $\mathrm{N}_{2}$ and $\mathrm{N}_{3}$ atoms of the piperazinyl group had little difference in electrical potential, but the $N_{3}$ atom had the strong $p-\pi$ conjugative effect with adjacent benzene ring. As a result, the $\mathrm{N}_{2}$ atom was vulnerable to electrophilic attack, and no ARI variant containing an exclusive protonation of the $\mathrm{N}_{3}$ atom was observed [16]. The global maxima value of the electrostatic potential on the surface in SAL was $+53.86 \mathrm{kcal} / \mathrm{mol}$, which corresponded to carboxylate group with a low $\mathrm{pKa}$ value $(\mathrm{pKa}=2.79)$. As result, the deprotonated $\mathrm{N}^{+}-\mathrm{H} \cdots \mathrm{O}$ hydrogen bond was formed in ARI-SAL salt. For ADI, the global and secondary maxima values were +49.71 and $+49.66 \mathrm{kcal} / \mathrm{mol}$, which corresponded to both of the carboxylate groups with identical nucleophilic reactivity, respectively. As expected, the deprotonated $\mathrm{N}^{+}-\mathrm{H} \cdots \mathrm{O}$ hydrogen-bonding contacts occurred in real ARI-ADI salt, where the stoichiometric ratio of ARI to ADI was 1:0.5.

\subsubsection{Hirshfeld Surface Analysis}

The 3D Hirshfeld surface and 2D fingerprint plots of two multicomponent crystals of ARI are given in Figure 7. In their 3D Hirshfeld surface, the large and deep red spots correspond to the close-contact $\mathrm{N}-\mathrm{H} \cdots \mathrm{O}$ interactions. The $\mathrm{H} \cdots \mathrm{H}$ contacts appear as scattered points in the middle region of the 2D fingerprint plots, which were the predominate type of interactions. The relative percentage contributions of $\mathrm{H} \cdots \mathrm{H}$ contacts in theARI-SAL salt were markedly lower than that of the ARI-ADI salt acetone hemisolvate and compensated by the $\mathrm{C} \cdots \mathrm{H} / \mathrm{H} \cdots \mathrm{C}$ contacts shown as a pair of "wings". However, these interactions displayed higher interatomic distance. Interactions with less interatomic distance are presented in fingerprint plots as pointy regions. The reciprocal $\mathrm{O} \cdots \mathrm{H}$ contacts, corre- 
sponding to $\mathrm{O}-\mathrm{H} \cdots \mathrm{O}, \mathrm{N}-\mathrm{H} \cdots \mathrm{O}$, and $\mathrm{C}-\mathrm{H} \cdots \mathrm{O}$ interactions, are presented as long, sharp, symmetrical spikes. Additionally, the $\mathrm{Cl} \cdots \mathrm{H}$ contacts, corresponding to the $\mathrm{Cl} \cdots \mathrm{H}-\mathrm{C}$, $\mathrm{Cl} \cdots \mathrm{H}-\mathrm{O}$ and $\mathrm{Cl} \cdots \mathrm{H}-\mathrm{N}$ interactions, appear as a pair of "wings" and have equivalent relative percentage contributions to their own Hirshfeld surfaces.
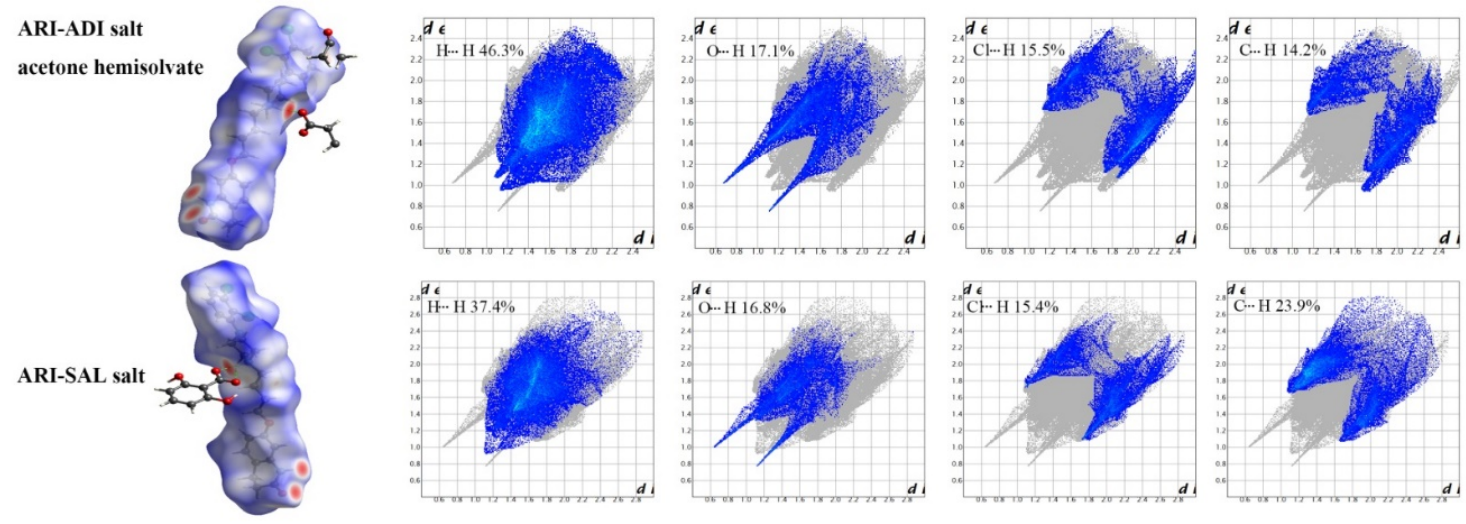

Figure 7. The 3D Hirshfeld surface and 2D fingerprint plots of two multicomponent crystals of ARI.

\subsection{Powder Hygroscopicity}

The moisture absorption is a crucial parameter that should be considered during the process of drug development, production, and storage. Therefore, the powder hygroscopicity was measured under $25^{\circ} \mathrm{C} / 80 \% \mathrm{RH}$ condition. Ten days later, the hygroscopic gain of ARI was $0.32 \pm 1.30 \%$. Meanwhile, ARI-SAL salt and ARI-ADI salt and its acetone hemisolvate showed greater hygroscopicity, with hygroscopic gains of $2.60 \pm 0.78 \%, 1.36 \pm 0.32 \%$, and $1.13 \pm 0.7 \%$, respectively. This might be presumably due to the presence of a polar group (i.e., $-\mathrm{OH}$ and $-\mathrm{COOH}$ ) introduced by synthesizing carboxylate salts, leading to the formation of hydrogen bonds with water molecules [33].

\subsection{Stability Test}

Moisture and high temperatures may cause the transformation of drug crystal forms and degradation, especially for solvates. Thus, close attention was paid to their stability under high humidity and high temperatures in this work. Figure 8 illustrates that the ARI-SAL salt was stable, while the ARI-ADI salt acetone hemisolvate was unstable under a high temperature. There were significant differences at the two-theta range of $19^{\circ}$ to $27^{\circ}$ compared with the starting PXRD pattern. In conjunction with DSC patterns of ARI-ADI salt acetone hemisolvate, we speculated that desolvation occurred under high temperatures. Unexpectedly, the PXRD pattern of the ARI-ADI salt was inconsistent with that of its acetone hemisolvate under high temperatures, demonstrating that ARI-ADI salt might be unstable under high temperatures.

(i)

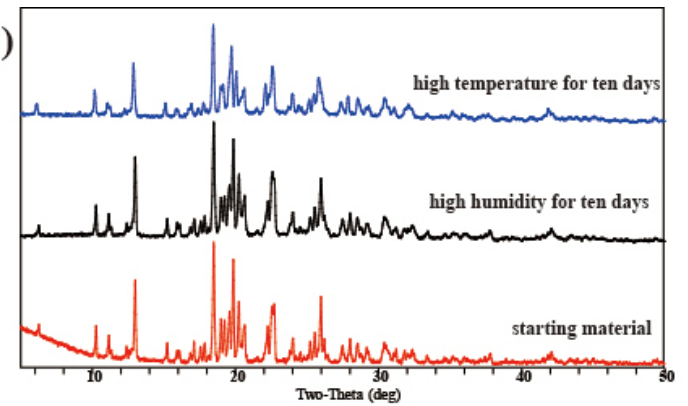

(ii )

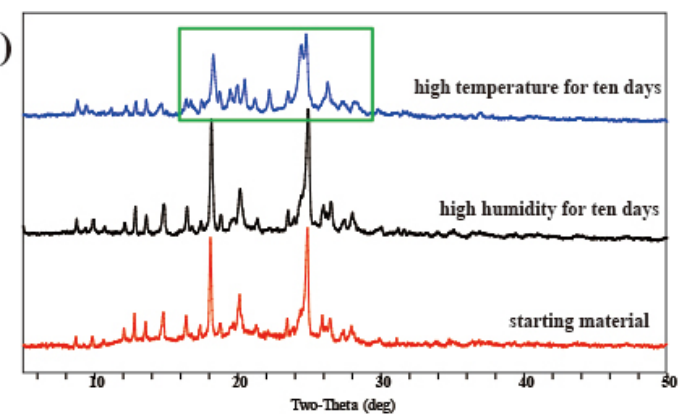

Figure 8. Results of stability testing of ARI-SAL salt (i) and ARI-ADI salt acetone hemisolvate (ii). 


\subsection{Solubility}

\subsubsection{Equilibrium Solubility Test}

The results of the equilibrium solubility experiments are summarized in Figure 9. The equilibrium solubility of the ARI-ADI salt in water, hydrochloric acid buffer, and acetate acid-sodium acetate buffered solution were $0.13,0.63$, and $0.15 \mathrm{mg} / \mathrm{mL}$, respectively, which was much better than that of the ARI and ARI-SAL salt but slightly smaller than that of the ARI-ADI salt acetone hemisolvate. However, the equilibrium solubility of the ARI-SAL salt was even worse than that of the ARI in both the hydrochloric acid buffer solution and acetate acid-sodium acetate buffered solution, though slightly better in water. In addition, the equilibrium solubility of ARI and its salts in the phosphate buffer solution were too low to be acquired accurately.

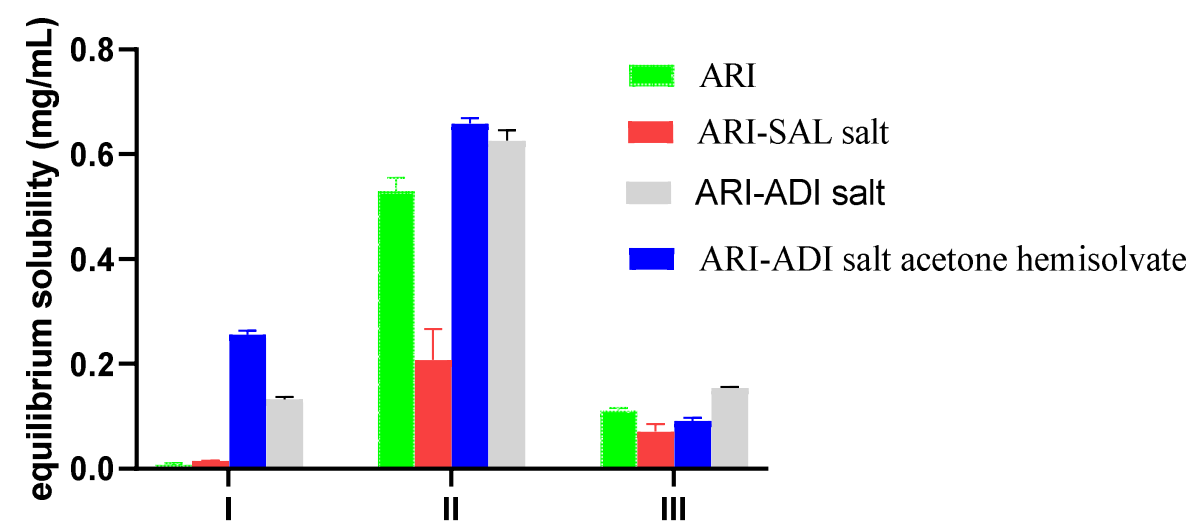

Figure 9. The equilibrium solubilities of ARI and its crystal salts in different solutions. I: water ( $\mathrm{pH}$ 7.0); II: hydrochloric acid buffer ( $\mathrm{pH}$ 1.2); III: acetate acid-sodium acetate buffered solution ( $\mathrm{pH}$ 4.5).

\subsubsection{IDR Test}

Given its kinetic nature, IDR assumes a better correlation with in vivo drug dissolution dynamics than solubility [34]. Thus, IDR studies were carried out at pH 1.2 in this work, and the results are summarized in Figure 10. The ARI held an IDR of $0.5051 \mathrm{mg} \cdot \mathrm{cm}^{-2} \cdot \mathrm{min}^{-1}$, while the IDR of the ARI-ADI salt, slightly lower than that of its acetone hemisolvate, significantly increased to $0.9263 \mathrm{mg} \cdot \mathrm{cm}^{-2} \cdot \mathrm{min}^{-1}$ and was about twice as much as that of the ARI. Not unexpectedly, the IDR of the ARI-SAL salt was only $0.3745 \mathrm{mg} \cdot \mathrm{cm}^{-2} \cdot \mathrm{min}^{-1}$, significantly lower than that of the ARI.

These findings indicated that ARI-ADI salt and its acetone hemisolvate had predictable advantages in vivo absorption over ARI-SAL salt and the untreated ARI. This may be due to many causes. First, the relatively higher hygroscopicity and lower melting point may lead to easier dissolution in an aqueous solvent, because of it demanding less lattice energy to break. Molecular constituents were also one of the important causes. The CCF of ARIADI salt was more soluble than that of the ARI-SAL salt, and their solubility behaviors follow the rule of thumb that the greater solubility of the $\mathrm{CCF}$, the more soluble the salt will be [18]. Finally, their spatial structures may also be associated with their differences in solubility. The ADI molecules linked with the solvent molecules to form a hydrophilic layer. As a result, water molecules permeate more easily into the layer stacking spatial structure and cause it to disintegrate in aqueous solvent. 


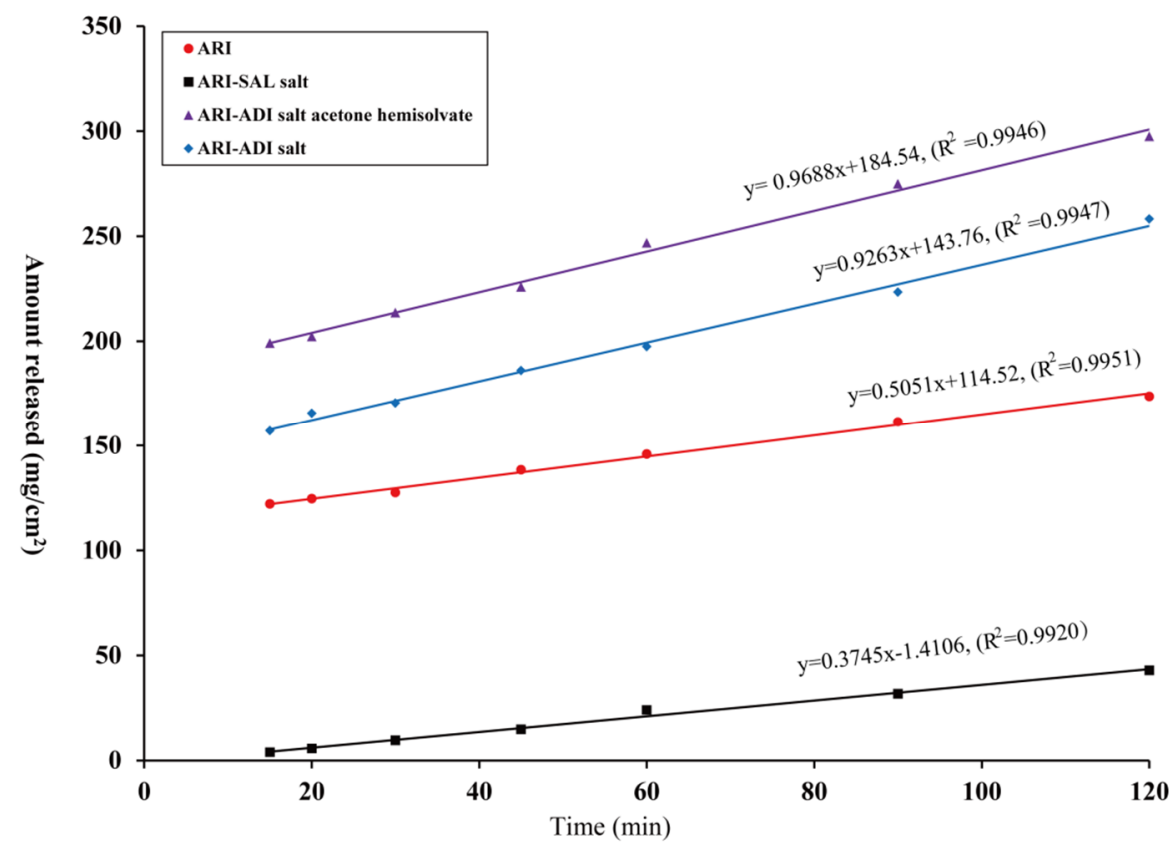

Figure 10. Intrinsic dissolution profiles of the ARI and its crystal salts in hydrochloric acid buffer (pH 1.2).

\section{Conclusions}

In this study, a new ARI-ADI salt and its acetone hemisolvate were successfully synthesized and fully characterized by various methods, along with a reported ARI-SAL salt. Their crystal structures revealed that the proton transferring occurred from a carboxylic group of CCF to the $\mathrm{N}_{2}$ atoms of the piperazine region from the ARI. Structural analysis showed that the ARI-SAL salt was arranged helically by two helices propagated along the $\mathrm{b}$ axis, while the ARI-ADI salt acetone hemisolvate presented a typical layer stacking with the help of weak $\mathrm{C}-\mathrm{H} \cdots \mathrm{Cl}$ and $\mathrm{C}-\mathrm{H} \cdots \pi$ hydrogen bonds. The reactivity of ARI and CCF was predicted by MEPS and matched well with their hydrogen bond schemes. Hirshfeld surface analysis was also used to clarify the intermolecular interactions. Furthermore, the ARI-ADI salt had a significant advantage over the ARI and ARI-SAL salt in terms of equilibrium solubility and IDR. This study provided a valuable insight into the formation of multicomponent pharmaceutical salts and presented potential alternative formulations of ARI.

Author Contributions: Conceptualization, D.Y. and J.T.; tests and data interpretation, Q.Z., Z.T., Y.W. and Y.Z.; writing—original draft preparation, Q.Z.; review and editing, Q.Z., Y.L. and G.G. All authors have read and agreed to the published version of the manuscript.

Funding: This research received no external funding.

Data Availability Statement: The data used to support the findings of this study are included within the article.

Conflicts of Interest: The authors declare no conflict of interest.

\section{Appendix A}

The supplementary crystallographic data for this paper have been deposited in the Cambridge Crystallographic Data Center and have reference numbers CCDC 1991810 and 2023732. These data can be obtained free of charge via http://www.ccdc.cam.ac.uk (accessed on 26 March 2021). 


\section{References}

1. Sethiya, A.; Agarwal, D.K.; Agarwal, S. Current Trends in Drug Delivery System of Curcumin and its Therapeutic Applications. Mini Rev. Med. Chem. 2020, 13, 1190-1232. [CrossRef]

2. Berry, D.J.; Steed, J.W. Pharmaceutical cocrystals, salts and multicomponent systems; intermolecular interactions and property based design. Adv. Drug Deliv. Rev. 2017, 117, 3-24. [CrossRef] [PubMed]

3. Diniz, L.F.; Carvalho, P.S., Jr.; Pena, S.A.C.; Gonçalves, J.E.; Souza, M.A.C.; de Souza Filho, J.D.; Bomfim Filho, L.F.O.; Franco, C.H.J.; Diniz, R.; Fernandes, C. Enhancing the solubility and permeability of the diuretic drug furosemide via multicomponent crystal forms. Int. J. Pharm. 2020. [CrossRef] [PubMed]

4. Clements, M.; Roex, T.L.; Blackie, M. Multicomponent Crystal Systems of Known Antimalarial Drug Molecules. ChemMedChem 2015, 10, 1786-1792. [CrossRef]

5. Sanphui, P.; Mishra, M.K.; Ramamurty, U.; Desiraju, G.R. Tuning mechanical properties of pharmaceutical crystals with multicomponent crystals: Voriconazole as a case study. Mol. Pharm. 2015, 12, 889-897. [CrossRef] [PubMed]

6. Elder, D.P.; Holm, R.; Diego, H.L. Use of pharmaceutical salts and cocrystals to address the issue of poor solubility. Int. J. Pharm. 2013, 453, 88-100. [CrossRef] [PubMed]

7. Prommer, E. Aripiprazole. Am. J. Hosp. Palliat. Care 2017, 34, 180-185. [CrossRef]

8. Cuomo, A.; Beccarini Crescenzi, B.; Goracci, A.; Bolognesi, S.; Giordano, N.; Rossi, R.; Facchi, E.; Neal, S.M.; Fagiolini, A. Drug safety evaluation of aripiprazole in bipolar disorder. Expert Opin. Drug Saf. 2019, 18, 455-463. [CrossRef]

9. Borrego-Sánchez, A.; Sánchez-Espejo, R.; Albertini, B.; Passerini, N.; Cerezo, P.; Viseras, C.; Sainz-Díaz, C.I. Ground Calcium Carbonate as a Low Cost and Biosafety Excipient for Solubility and Dissolution Improvement of Praziquantel. Pharmaceutics 2019, 11, 533. [CrossRef]

10. Lyszczarz, E.; Hofmanova, J.; Szafraniec-Szczesny, J.; Jachowicz, R. Orodispersible films containing ball milled aripiprazolepoloxamer(R)407 solid dispersions. Int. J. Pharm. 2020. [CrossRef]

11. Gao, L.; Zhang, X.R.; Chen, Y.F.; Liao, Z.L. A new febuxostat imidazolium salt hydrate: Synthesis, crystal structure, solubility, and dissolution study. J. Mol. Struct. 2019, 1176, 633-640. [CrossRef]

12. Miraglia, N.; Agostinetto, M.; Bianchi, D.; Valoti, E. Enhanced oral bioavailability of a novel folate salt: Comparison with folic acid and a calcium folate salt in a pharmacokinetic study in rats. Minerva Ginecol. 2016, 68, 99-105.

13. Freire, E.; Polla, G.; Baggio, R. Aripiprazole salts I Aripiprazole nitrate. Acta Crystallogr. C 2012, 68 Pt 4, o170-o173. [CrossRef]

14. Freire, E.; Polla, G.; Baggio, R. Aripiprazole salts. II. Aripiprazole perchlorate. Acta Crystallogr. C 2012, 68 Pt 6, o235-o239. [CrossRef]

15. Freire, E.; Polla, G.; Baggio, R. Aripiprazole salts. III. Bis(aripiprazolium) oxalate-oxalic acid (1/1). Acta Crystallogr. C 2013, 69 Pt 2, 186-190. [CrossRef]

16. Freire, E.; Polla, G.; Baggio, R. Aripiprazole salts IV. Anionic plus solvato networks defining molecular conformation. J. Mol. Struct. 2014, 1068, 43-52. [CrossRef]

17. Nanubolu, J.B.; Sridhar, B.; Ravikumar, K.; Cherukuvada, S. Adaptability of aripiprazole towards forming isostructural hydrogen bonding networks in multi-component salts: A rare case of strong $\mathrm{O}-\mathrm{H} \cdots \mathrm{O}-\leftrightarrow \leftrightarrow$ weak $\mathrm{C}-\mathrm{H} \cdots \mathrm{O}$ mimicry. CrystEngComm 2013, 15, 4321-4335. [CrossRef]

18. Zhao, Y.; Sun, B.; Jia, L.; Wang, Y.; Wang, M.; Yang, H.; Qiao, Y.; Gong, J.; Tang, W. Tuning Physicochemical Properties of Antipsychotic Drug Aripiprazole with Multicomponent Crystal Strategy Based on Structure and Property Relationship. Cryst. Growth. Des. 2020, 20, 3747-3761. [CrossRef]

19. SAINT Version 7.68A. Software for the CCD Detector System; Bruker AXS Inc: Madison, WI, USA, 2009.

20. Sheldrick, G.M. SADABS, Bruker/Siemens Area Detector Absorption Correction Program; University of Göttingen: Göttingen, Germany, 1998.

21. Sheldrick, G.M. A short history of SHELX. Acta Crystallogr. A 2008, 64, 112-122. [CrossRef] [PubMed]

22. Sheldrick, G.M. SHELXL2015, Program for Crystal Structure Refinement; University of Göttingen: Göttingen, Germany, 2015.

23. Pennington, W. DIAMOND—Visual Crystal Structure Information System. J. Appl. Crystallogr. 1999, 32, 1028-1029. [CrossRef]

24. Sedghiniya, S.; Soleimannejad, J.; Janczak, J. The salt-cocrystal spectrum in salicylic acid-adenine: The influence of crystal structure on proton-transfer balance. Acta Crystallogr. C Struct. Chem. 2019, 75 Pt 4, 412-421. [CrossRef]

25. Sanphui, P.; Bolla, G.; Nangia, A. High Solubility Piperazine Salts of the Nonsteroidal Anti-Inflammatory Drug (NSAID) Meclofenamic Acid. Cryst. Growth. Des. 2012, 12, 2023-2036. [CrossRef]

26. Khan, M.F.; Nahar, N.; Rashid, R.B.; Chowdhury, A.; Rashid, M.A. Computational investigations of physicochemical, pharmacokinetic, toxicological properties and molecular docking of betulinic acid, a constituent of Corypha taliera (Roxb.) with Phospholipase A2 (PLA2). BMC complement. Altern. Med. 2018, 18, 48-62. [CrossRef]

27. Lu, T.; Chen, F. Multiwfn: A multifunctional wavefunction analyzer. J. Comput. Chem. 2012, 33, 580-592. [CrossRef] [PubMed]

28. Manzetti, S.; Lu, T. The geometry and electronic structure of Aristolochic acid: Possible implications for a frozen resonance. $J$. Phys. Org. Chem. 2013, 26, 473-483. [CrossRef]

29. Zhang, X.; Zhou, L.; Wang, C.; Li, Y.; Wu, Y.; Zhang, M.; Yin, Q. Insight into the Role of Hydrogen Bonding in the Molecular Self-Assembly Process of Sulfamethazine Solvates. Cryst. Growth. Des. 2017, 17, 6151-6157. [CrossRef]

30. Spackman, M.A.; Jayatilaka, D. Hirshfeld Surface Analysis. CrystEngComm 2009, 11, 19-32. [CrossRef] 
31. Yang, D.; Cao, J.; Jiao, L.; Yang, S.; Zhang, L.; Lu, Y.; Du, G. Solubility and stability advantages of a new cocrystal of berberine chloride with fumaric acid. ACS Omega 2020, 4, 8283-8292. [CrossRef] [PubMed]

32. Steiner, T. Competition of hydrogen-bond acceptors for the strong carboxyl donor. Acta Crystallogr. B 2001, 57, 103-106. [CrossRef] [PubMed]

33. Newman, A.W.; Reutzel-Edens, S.M.; Zografi, G. Characterization of the "hygroscopic" properties of active pharmaceutical ingredients. J. Pharm. Sci. 2008, 97, 1047-1059. [CrossRef] [PubMed]

34. Shevchenko, A.; Bimbo, L.M.; Miroshnyk, I.; Haarala, J.; Jelínková, K.; Syrjänen, K.; Veen, B.; Kiesvaara, J.; Santos, H.A.; Yliruusi, J. A new cocrystal and salts of itraconazole: Comparison of solid-state properties stability and dissolution behavior. Int. J. Pharm. 2012, 436, 403-409. [CrossRef] [PubMed] 